\title{
The crown-rump length measurement - ISUOG criteria and clinical practice
}

\author{
Dominik Jakubowski'®], Magdalena Bednarek-Jedrzejek²®, Daria Salloum¹, \\ Andrzej Torbe ${ }^{2}$, , Sebastian Kwiatkowski² \\ ${ }^{1}$ Pomeranian Medical University, Szczecin, Poland \\ ${ }^{2}$ Clinical Department of Obstetrics and Gynecology, Pomeranian Medical University, Szczecin, Poland
}

\begin{abstract}
Objectives: Significance of the crown-rump length (CRL) measurement criteria in the assessments of gestational age and actual precision in daily clinical practice.

Material and methods: We recruited 806 pregnant women with singleton pregnancy and history of regular menstrual periods.We analysed retrospectively CRL measurements obtained during routine first trimester scan performed between $11+0$ and $13+6$ weeks gestation. Gestational age was calculated using both the last menstrual period (LMP) and the CRL. The images of the CRL measurements were assessed by the expert. The visual analysis of the images in terms of meeting the five criteria recommended by the International Society of Ultrasound in Obstetrics and Gynecology (ISUOG) was performed. Statistical analysis were used to assess how the above-mentioned criteria influenced calculation of the gestational age.

Results: The study showed 323 out of 806 of the CRL measurements (40.1\%) were qualified by a specialist as accurate, 279 (34.6\%) as inaccurate, and 204 (25.3\%) as inaccurate, but not changing the duration of a pregnancy. With the application in the assessment of the five criteria of the ISOUG 217 (26.9\%), the following results of qualification were obtained: accurate - fulfilled $\geq 4$, inaccurate $341(42.3 \%)$ - fulfilled $\leq 2$, whereas inaccurate, but not changing the duration of a pregnancy $248(30.8 \%)-3$ criteria fulfilled. We found that only the neutralof the fetus demonstrated a significant corellation with the assessment of the duration of a gestation.
\end{abstract}

Conclusions: $a$ ) the accurate audit of the CRL measurements is recommended; $b$ ) neutral position of the fetus is the most important criterion out of 5 .

Key words: CRL, gestation, early pregnancy

Ginekologia Polska 2020; 91, 11:674-678

\section{INTRODUCTION}

Determining the gestation age accurately is one of the key elements influencing the provision of accurate perinatological, and obstetric care for a patient. In Poland, the assessment of gestational age (GA) is conducted with the application of two methods.

The first method is based on the date of the last menstrual period (LMP), which is easy to perform and inexpensive. However, the following conditions had to be fulfilled for this method to give accurate estimations of the gestational age: regular menstrual cycle, fertilisation in the middle of the cycle, accurate information of the first day of the LMP must be provided by the women. Determining gestational age precisely on the basis of the LMP would be possible if the exact dates of: ovulation, fertilisation, and implantation of an embryo were known, for instance in pregnancies aris- ing using ART (Assisted Reproductive Technology) [1]. Even in cases of accurate recollection of the date of LMP, delayed ovulation can cause discrepancies between gestational age calculated using LMP and with the use of different methods.

The second method uses an assessment of crown-rump length (CRL). CRL measurement can be obtained during routine ultrasound scan in first trimester and is described as the length of the fetus from top of the head to the bottom of the rump (buttocks). The CRL measurement is seen as the most sensitive predictor of gestational age in the first trimester of pregnancy [2]. The International Society of Ultrasound in Obstetrics and Gynecology (ISOUG) recommends determining the duration of pregnancy based on CRL between 8 and 14 weeks as the most reliable method [3].

To ensure the objective assessment of crown-rump length, the ISOUG proposed five criteria to increase the 


\begin{tabular}{|c|c|c|c|}
\hline Week 11 - CRL 50 mm & Week 12 - CRL $63 \mathrm{~mm}$ & Week $13-$ CRL 76 mm & Week $13+6-$ CRL $88 \mathrm{~mm}$ \\
\hline$-5 \mathrm{~mm}=$ week $10+4 \mathrm{~mm}$ & $-5 \mathrm{~mm}=$ week $11+4$ & $-5 \mathrm{~mm}=$ week $12+4$ & $-5 \mathrm{~mm}+$ week $13+3$ \\
\hline$-10 \mathrm{~mm}=$ week $10+1$ & $-10 \mathrm{~mm}=$ week $11+1$ & $-10 \mathrm{~mm}=$ week $12+1$ & $-10 \mathrm{~mm}=$ week $13+1$ \\
\hline$+5 \mathrm{~mm}=$ week $11+3$ & $+5 \mathrm{~mm}=$ week $12+2$ & $+5 \mathrm{~mm}=$ week $13+2$ & $+5 \mathrm{~mm}=$ week $14+1$ \\
\hline$+10 \mathrm{~mm}=$ week $11+5$ & $+10 \mathrm{~mm}=$ week $12+5$ & $+10 \mathrm{~mm}=$ week $13+5$ & \\
\hline
\end{tabular}

CRL - crown-rump length

\begin{tabular}{|c|c|c|c|}
\hline Week 11 - CRL 43 mm & Week 12 - CRL $55 \mathrm{~mm}$ & Week 13 - CRL $67 \mathrm{~mm}$ & Week $13+6$ - CRL $78 \mathrm{~mm}$ \\
\hline$-5 \mathrm{~mm}=$ week $10+4 \mathrm{~mm}$ & $-5 \mathrm{~mm}=$ week $11+4$ & $-5 \mathrm{~mm}=$ week $12+4$ & $-5 m m+$ week $13+3$ \\
\hline$-10 \mathrm{~mm}=$ week $10+1$ & $-10 \mathrm{~mm}=$ week $11+1$ & $10 \mathrm{~mm}=$ week $12+2$ & $10 \mathrm{~mm}=$ week $13+1$ \\
\hline$+5 \mathrm{~mm}=$ week $11+3$ & $+5 \mathrm{~mm}=$ week $12+3$ & $+5 \mathrm{~mm}=$ week $13+2$ & $+5 \mathrm{~mm}=$ week $14+1$ \\
\hline$+10 \mathrm{~mm}=$ week $11+6$ & $+10 \mathrm{~mm}=$ week $12+6$ & $+10 \mathrm{~mm}=$ week $13+5$ & $+10 \mathrm{~mm}=$ week $14+3$ \\
\hline
\end{tabular}

$\mathrm{CRL}$ - crown-rump length

precision of the conducted measurements. These include accurate magnification of the image, neutrality of the fetus, horizontal position of the fetu, accurate placement of the callipers, and the presence of pocket of amniotic fluid under the foetus chin.

Even small inaccuracies, as small as $5 \mathrm{~mm}$ to $10 \mathrm{~mm}$, in the CRL measurement can cause significant differences in calculation of the gestational age. Examples of how inaccurate measurement of CRL can affect calculation of the gestational age can be seen in the tables (Tab. 1-3).

\section{Objectives}

The aim of the study was to evaluate the significance of the CRL measurement criteria in the assessments of gestational age and its actual precision in daily clinical practice.

\section{MATERIAL AND METHODS}

There were 806 women with singleton pregnancies and known date of LMP included into the study. All women had history of regular menstrual periods (28-35 days) and underwent a routine first trimester scan in our Prenatal Assessment Clinic between January 2017 and December 2019. Patients with irregular menstruation cycle and lactating patients were excluded from the study. CRL measurements obtained during routine ultrasound scans were assessed retrospectively by experts in fetal medicine ultrasound.. The physicians who took the measurements were obstetrics\&gynecology specialists with experience in ultrasonography. Moreover, all of them were certified by PTGiP (minimum of 5 years) and FMF. The measurements were taken on GE Voluson E6 ultrasonograph in Prenatal Outpatient Clinic belonging to the Department of Obstet- rics and Gynecology of Pomeranian Medical University in Szczecin. In all of the cases the duration of the pregnancy was established using two methods: based on the LMP and based on the CRL.

First, CRL pictures were assessed by an expert in fetal medicine. ISUOG criteria were applied when assessing CRL measurements. Said expert is a physician, specializing in obstetrics\&gynecology and fetal medicine (with over 10 years of experience) certified by FMF (for over 12 years) and audited by FMF for over 6 years. The measurements were divided into three categories: correct, incorrect and incorrect, but with no impact on the pregnancy's duration. The difference in the duration of a pregnancy determined on the basis of the LMP, and between the duration of a pregnancy determined on the basis of the $C R L$, in particular groups was compared.

It was proposed that the population be divided into three separate categories depending on the number of fulfilled criteria. The measurements fulfilling four to five criteria were qualified as accurate. The measurements fulfilling three criteria were found to be inaccurate, but not changing the duration of a pregnancy, whereas the measurements fulfilling two or fewer criteria were found to be inaccurate. Afterwards, the difference in the duration of a pregnancy determined on the basis of the LMP, and between the duration of a pregnancy determined on the basis of the $C R L$, in particular groups was compared.

The next stage involved the assessment of the significance of the particular criteria of the ISOUG for the assessment of the duration of a pregnancy determined with the application of the CRL. For each criterion, the difference between the gestational age calculated from LMP, and use of the CRL, was assessed. 


\begin{tabular}{|c|c|c|c|}
\hline Week 11 - CRL 36 mm & Week $13-$ CRL 47 mm & Week 13 - CRL $59 \mathrm{~mm}$ & Week $13+6-$ CRL $70 \mathrm{~mm}$ \\
\hline$-5 \mathrm{~mm}=$ week $10+3 \mathrm{~mm}$ & $-5 \mathrm{~mm}=$ week $11+4$ & $-5 \mathrm{~mm}=$ week $12+4$ & $-5 \mathrm{~mm}+$ week $13+3$ \\
\hline$-10 \mathrm{~mm}=$ week 10 & $10 \mathrm{~mm}=$ week 11 & $-10 \mathrm{~mm}=$ week $12+1$ & $-10 \mathrm{~mm}=$ week 13 \\
\hline$+5 \mathrm{~mm}=$ week $11+3$ & $+5 \mathrm{~mm}=$ week $12+3$ & $+5 \mathrm{~mm}=$ week $13+3$ & $+5 \mathrm{~mm}=$ week $14+2$ \\
\hline$+10 \mathrm{~mm}=$ week $11+6$ & $+10 \mathrm{~mm}=$ week $12+6$ & $+10 \mathrm{~mm}=$ week $13+5$ & $+10 \mathrm{~mm}=$ week $14+5$ \\
\hline
\end{tabular}

$\mathrm{CRL}$ - crown-rump length

\begin{tabular}{|l|c|c|c|c|}
\hline $\begin{array}{l}\text { Table 4. The assessment of the particular criteria } \\
\text { Criterion according } \\
\text { to the ISOUG }\end{array}$ & $\begin{array}{c}\text { Number of } \\
\text { accurate } \\
\text { measurements }\end{array}$ & $\begin{array}{c}\text { Number of } \\
\text { inaccurate } \\
\text { measurements }\end{array}$ & $\begin{array}{c}\text { Difference between GA } \\
\text { on the basis of the LMP, and GA } \\
\text { on the basis of the CRL, among } \\
\text { accurate measurements }\end{array}$ & $\begin{array}{c}\text { Difference between GA } \\
\text { on the basis of the LMP, and GA } \\
\text { on the basis of the CRL, among } \\
\text { inaccurate measurements }\end{array}$ \\
\hline Image enlargement & 458 & 348 & $p=0.624$ & $p=0.489$ \\
\hline Neutral position & 319 & 487 & $p=0.002$ & $p=0.012$ \\
\hline Horizontal position & 593 & 213 & $p=0.527$ & $p=0.204$ \\
\hline Setting callipers & 341 & 465 & $p=0.127$ & $p=0.152$ \\
\hline Presence of fluid under the chin & 434 & 372 & $p=0.209$ & $p=0.153$
\end{tabular}

CRL — crown-rump length; GA — gestational age; ISUOG — the International Society of Ultrasound in Obstetrics and Gynecology; LMP — last menstrual period

Lastly, the repeated division of the images in terms of the fulfilled ISOUG criteria. As accurate measurements, those fulfilling four to five criteria were assessed; it was required that they had been positively assessed in terms of the neutral position. The measurements fulfilling three criteria were found to be inaccurate, but not changing the duration of a pregnancy, whereas these which fulfilled two or fewer criteria, and which also received a negative assessment in terms of the neutral position were found to be inaccurate. The analysis of the difference in the duration of a pregnancy determined with the application of the LMP and the CRL was repeated again.

The statistics were made using the Statistical Package for Social Sciences (SSPS TM) program. The Shapiro-Wilk test showed that the data does not distribute normally. Next, the U-Mann-Whitney test was conducted in order to compare the categories. The statistical significance level was set at $\mathrm{p}<0.05$.

\section{RESULTS}

Out of 806 of the CRL measurements, 323 (40.1\%) were qualified as accurate, 279 (34.6\%) as inaccurate, and $204(25.3 \%)$ as inaccurate, but not changing the duration of a pregnancy. 527 , i.e. $65.4 \%$ of the measurements of crown-rump length made it possible to ensure the accurate assessment of gestational age. A statistically-significant difference between the duration of a pregnancy determined with the application of the LMP and USG ( $p=0.003$ ) was observed in the group of inaccurate measurements, whereas in the group with accurate measurements and inaccurate, but not changing the duration of a pregnancy, no statistically significant difference was observed.

Applying in the assessment of the five criteria of the ISOUG, it was determined that 217 (26.9\%) of the measurements were accurate, and 341 (42.3\%) inaccurate, whereas the number of inaccurate measurements, not changing the duration of a pregnancy, was established as 248 (30.8\%). Similarly, only $57.7 \%$ of the CRL measurements made it possible to ensure the proper assessment and determine the duration of a pregnancy. A statistically-significant difference between the duration of a pregnancy according to the LMP and the CRL in the group of inaccurate measurements $(p=0.025)$ was demonstrated again.

Also, 348 (43.2\%) of the measurements were found to be inaccurate, and 458 (56.8\%) as accurate, in terms of the criterion of image enlargement. A statistically-significant difference in the duration of a pregnancy determined on the basis of the LMP and the CRL was not demonstrated, either in the group found to be inaccurate or the one found to be accurate.

In terms of the neutrality of the fetus, 487 (60.4\%) of the assessments were found to be inaccurate, and 319 (39.6\%) as accurate. In the group of inaccurate measurements, and also that of the accurate ones, a statistically-significant difference between the duration of a pregnancy determined on the basis of the LMP, and sometimes the duration of a pregnancy determined on the basis of the $\mathrm{CRL}$, was observed.

In 213 (26.4\%) of the measurements, the horizontal position of the fetus was determined as inaccurate, whereas 
it was found to be accurate in 593 (73.6\%) of the measurements. A statistically-significant difference in the duration of a pregnancy determined on the basis of the LMP and the CRL in both of the groups was not demonstrated.

In the case of the criterion of accurate placement of the callipers, 465 (57.7\%) of the measurements were assessed to be inaccurate, and 341 (42.3\%) to be accurate. A statistically-significant difference in the duration of a pregnancy determined on the basis of the LMP and the CRL was not observed.

The presence of fluid under the chin was found to be inaccurate in 372 (46.2\%) of the measurements, and it was found to be accurate in 434 (53.8\%) of them. No statistically-significant difference between the duration of a pregnancy determined on the basis of the LMP and the duration of a pregnancy determined on the basis of the CRL was observed in both of the groups. The assessment of the particular criteria was presented in Table 4.

At the following stage, 189 (23.5\%) of the measurements were described as accurate, i.e. fulfilling four to five criteria, and that included the positive assessment of the neutral position. The measurements of $90(11.2 \%)$ were found to be inaccurate, but not changing the duration of a pregnancy, i.e. fulfilling three criteria, whereas 527 (63.3\%) were found to be inaccurate, i.e. fulfilling two or fewer of the criteria; this group included also the measurements in which the neutral position was assessed negatively. A difference in the duration of a pregnancy determined on the basis of the LMP, and in the duration of a pregnancy determined on the basis of the CRL in the group of measurements determined to be inaccurate, and also in the group of accurate measurements and those found to be inaccurate, but not changing the duration of a pregnancy.

\section{DISCUSSION}

Presently, ultrasonography is replacing the traditional method of calculating gestational age based on the LMP. It is thought that the measurement of crown-rump length is the most accurate method of calculating gestational age in first trimester [4]. CRL can be measured very early in the first trimester and attempts were made to calculate gestational age using these measurements as early as or before 9 weeks of pregnancy [5]. However current consensus on the most accurate assessment of gestational age using CRL advises performing these measurements between the $11^{\text {th }}$ and $13^{\text {th }}+6$ weeks of pregnancy.

Applying as the basis gestational age determined on the basis of the CRL parameter, results in a significant reduction in the number of premature pregnancies, postmature pregnancies [6], and also improved the effectiveness of screening of chromosomal disorders [6]. It is connected with frequently erroneous information provided by a pregnant woman on the last menstrual period, which causes a mistake in determining gestational age, and as a consequence, underestimating or overestimating it. That, in turn, leads to the misdiagnosing of premature births.

Due to the differences between gestational age determined with the application of the LMP, and with the application of USG, it is recommended to base on the EUS measurements in the case of a difference of no fewer than seven days [8].

A key element of determining gestational age accurately is the precise determination of the CRL measurement. The problem related to the subjective assessment of this parameter is raised, among others, due to imprecise criteria and the risk of different interpretation of the measurements by various specialists. According to the literature, like in our analysis, the most important criterion is the neutral position [9]. In accordance with the assessment of specialists, the assessment of the above-mentioned criterion involves a problem with determining what deviation should be interpreted as a position making it impossible to accurately assess the crown-rump length.

Another aspect is the influence of the inaccurate assessment of the CRL parameter on the diagnostics of chromosomal disorders. It is reported that a measurement error in the assessment of crown-rump length may result in reducing the detection of the trisomy of the $21^{\text {st }}$ chromosome, and increasing the number of distorted (underestimated) results [10]. In the literature, we can also find a correlation between a small crown-rump length and a higher risk of chromosomal anomalies [11].

Our paper proved that even in a centre specialising in prenatal diagnostics, a significant percentage of examinations include deviations from the recommended rules of measurements, which may influence determining gestational age, and, ipso facto, affect the supervision of obstetric personnel in the second half of a pregnancy (suspicion of IUGR, and necessity of inducing a delivery). A problem related to the accurate assessment of the CRL is raised in the literature, which suggests that the issue requires further studies, and a debate on the criteria proposed by the ISOUG [12]. One of the elements of the discussion should be the importance of particular criteria in the assessment of an accurate measurement or reducing their number. Our analysis brought forth the conclusion that the most important criterion is the neutral position. Yet, the issue needs commencing collaboration between various facilities, and then repeating studies on a larger group of patients. Conducting standardisation exercises for USG specialists would also increase the percentage of accurately performed examinations [13].

An assessment conducted by an expert, and on the basis of criteria of the ISOUG, is identical in terms of determining the duration of a pregnancy, which may be applied by 
conducting an audit in which implementation should be sought for. One of the proposed forms of audits is introducing the assessment of the CRL measurements by specialists according to objective, such as the neutral position. It was observed that ensuring objective assessments results in a lower percentage of inaccurate measurements, and makes the measurements more repeatable [14].

\section{CONCLUSIONS}

The accurate audit of the CRL measurements are recommended in every group of researchers regardless of experience. Not all of the criteria recommended by the ISOUG influence the assessment of gestational age in the same manner; studies on a larger population are required in order to verify the significance of particular criteria. An assessment by an expert in prenatal diagnostics is identical to the detailed analysis of the criteria of the ISOUG, and may be seen as a form of audit.

\section{Conflict of interest}

None declared.

\section{REFERENCES}

1. Wennerholm UB, Bergh $\mathrm{C}$, Hagberg $\mathrm{H}$, et al. Gestational age in pregnancies after in vitro fertilization: comparison between ultrasound measurement and actual age. Ultrasound Obstet Gynecol. 1998; 12(3): 170-174, doi: 10.1046/j.1469-0705.1998.12030170.x, indexed in Pubmed: 9793188

2. Drumm JE. The prediction of delivery date by ultrasonic measurement of fetal crown-rump length. Br J Obstet Gynaecol. 1977; 84(1): 1-5, doi: 10.1111/j.1471-0528.1977.tb12457.x, indexed in Pubmed: 843465.

3. Salomon LJ, Alfirevic Z, Bilardo CM, et al. ISUOG practice guidelines: performance of first-trimester fetal ultrasound scan. Ultrasound Obstet
Gynecol. 2013; 41(1): 102-113, doi: 10.1002/uog.12342, indexed in Pubmed: 23280739.

4. Butt K, Lim KI, Butt K, et al. Determination of gestational age by ultrasound. J Obstet Gynaecol Can. 2014; 36(2): 171-181, doi: 10.1016/S17012163(15)30664-2, indexed in Pubmed: 24518917.

5. Cadkin A. Crown-rump length dating of pregnancy at less than nine weeks' gestation. American Journal of Obstetrics and Gynecology. 1992; 166(1): 269, doi: 10.1016/0002-9378(92)91880-j.

6. Mongelli M, Wilcox M, Gardosi J. Estimating the date of confinement: ultrasonographic biometry versus certain menstrual dates. Am J Obstet Gynecol. 1996; 174(1 Pt 1): 278-281, doi: 10.1016/s0002-9378(96)704088, indexed in Pubmed: 8572021.

7. van Heesch PN, Struijk PC, Laudy JAM, et al. Estimating the effect of gestational age on test performance of combined first-trimester screening for Down syndrome: a preliminary study. J Perinat Med. 2010; 38(3): 305-309, doi: 10.1515/jpm.2010.033, indexed in Pubmed: 20121529.

8. Blondel B, Morin I, Platt RW, et al. Algorithms for combining menstrual and ultrasound estimates of gestational age: consequences for rates of preterm and postterm birth. BJOG. 2002; 109(6): 718-720, doi: 10.1111/j. 1471-0528.2002.01068.x, indexed in Pubmed: 12118654.

9. Roux N, Dhombres F, Friszer $S$, et al. Comment évaluer la flexion de l'embryon lors de la mesure de la longueur cranio-caudale. Gynécologie Obstétrique \& Fertilité. 2016; 44(3): 146-150, doi: 10.1016/j. gyobfe.2016.02.007.

10. Kagan KO, Hoopmann M, Baker A, et al. Impact of bias in crown-rump length measurement at first-trimester screening for trisomy 21. Ultrasound Obstet Gynecol. 2012; 40(2): 135-139, doi: 10.1002/uog.11095, indexed in Pubmed: 22262465.

11. Sagi-Dain L, Peleg A, Sagi S. First-Trimester crown-rump length and risk of chromosomal aberrations-a systematic review and meta-analysis. Obstet Gynecol Surv. 2017; 72(10): 603-609, doi: 10.1097/OGX.0000000000000490, indexed in Pubmed: 29059452.

12. Dhombres F, Roux N, Friszer S, et al. Quality of first-trimester measurement of crown-rump length. Am J Obstet Gynecol. 2014; 211(6): 672.e1672.e5, doi: 10.1016/j.ajog.2014.06.012, indexed in Pubmed: 24912098.

13. Sarris I, loannou C, Dighe M, et al. Standardization of fetal ultrasound biometry measurements: improving the quality and consistency of measurements. Ultrasound Obstet Gynecol. 2011; 38(6): 681-687, doi: 10.1002/uog.8997, indexed in Pubmed: 22411446.

14. Wanyonyi SZ, Napolitano R, Ohuma EO, et al. Image-scoring system for crown-rump length measurement. Ultrasound Obstet Gynecol. 2014; 44(6): 649-654, doi: 10.1002/uog.13376, indexed in Pubmed: 24677327. 